\title{
ADIÇÃO DE RESÍDUO INDUSTRIAL NO DESENVOLVIMENTO DE MASSAS CERÂMICAS PARA O ARTESANATO DO CABO DE SANTO AGOSTINHO - PERNAMBUCO
}

Germannya D’Garcia de Araújo Silva

Laboratório O Imaginário - Dep. Design - Universidade Federal de Pernambuco germannyadgarcia@gmail.com

Juliana Carvalho da Silva

Laboratório de Cerâmicas Especiais - Dep. Eng. Mecânica - Universidade

Federal de Pernambuco

julianacarvalhodasilva0@gmail.com

Tiberio Cesar Macedo Tabosa

Laboratório O Imaginário - Dep. Design - Universidade Federal de Pernambuco ttabosa@hotmail.com

Ana Maria Queiroz de Andrade

Laboratório O Imaginário - Dep. Design - Universidade Federal de Pernambuco anamariadeandrade@gmail.com

Virginia Pereira Cavalcanti

Laboratório O Imaginário - Dep. Design - Universidade Federal de Pernambuco cavalcanti.virginia@gmail.com

Resumo: Neste artigo foram avaliadas as propriedades físicas e mecânicas de duas massas cerâmicas a base de resíduos cerâmicos industriais desenvolvidas pelos técnicos do Laboratório de Design O Imaginário da UFPE para a produção de produtos artesanais cerâmicos do Centro de Artesanato Arq. Wilson Campos Júnior. As massas desenvolvidas foram caracterizadas por análise química e por ensaios cerâmicos normatizados: Retração linear total (\%); Absorção de água (\%); Módulo de Ruptura à Flexão $\left(\mathrm{Kgf} / \mathrm{cm}^{2}\right)$; Perda ao fogo (\%); e Cor após queima. Como principais resultados observou-se que a inserção de diferentes percentuais do resíduo industrial na argila in natura melhoraram suas propriedades físicas e atendem aos requisitos técnicos e estéticos para fabricação da cerâmica artística e utilitária do grupo ceramista apoiado pelo Programa Petrobras Desenvolvimento e Cidadania.

Palavras-chave: Reaproveitamento de material, Cerâmica Vermelha, Resíduo Industrial, Utilitários de mesa 


\section{INTRODUÇÃO}

A produção de cerâmica vermelha no Cabo de Santo Agostinho é uma das atividades que remonta aos tempos da colonização. Durante séculos, as olarias de propriedade dos engenhos de açúcar produziram apenas tijolos e telhas para atender, exclusivamente, às necessidades da principal atividade econômica da zona da mata sul de Pernambuco. Com o passar do tempo, as olarias começaram a confeccionar moringas, jarras, panelas, potes, alguidares e pratos de curau ${ }^{1}$.

A extração da matéria prima para a produção das peças, a argila, sempre foi considerada uma atividade não econômica, sendo autorizada por SUAPE ${ }^{2}$ por considerar o volume mensal, menos de oito toneladas/mês, apenas para a produção artesanal dos produtos. Atualmente, com o desenvolvimento econômico da região, tais jazidas estão sendo aterradas para a instalação de indústrias de grande porte. Esta situação gerou a urgente necessidade de se estabelecer alternativas para a manutenção do fornecimento de matéria prima aos ceramistas do Cabo.

Diante deste cenário, o Laboratório O Imaginário submeteu e aprovou, no ano de 2013, o projeto "Cerâmica Artesanal do Cabo de Santo Agostinho: Centro de Artesanato Arquiteto Wilson de Queiroz Campos Júnior" ao edital do Programa Petrobras Desenvolvimento e Cidadania. O Imaginário é um Laboratório de pesquisa e extensão multidisciplinar, vinculado ao Departamento de Design e de Cultura da Universidade Federal de Pernambuco composto por profissionais, professores e estudantes de diversas áreas do conhecimento, que atuam com foco no design ${ }^{3}$ como instrumento a serviço da sustentabilidade, ambiental, econômica e social. É o resultado da evolução de projetos de pesquisa e extensão, que somavam esforços para a inserção do design tanto no âmbito industrial quanto artesanal. Sua missão é oferecer soluções de design baseadas em pesquisa e que estejam comprometidas com o usuário e o desenvolvimento sustentável de processos e sistemas. (ANDRADE; CAVALCANTI, 2006)

As abordagens metodológicas utilizadas pelo Laboratório O Imaginário tanto no ambiente artesanal quanto no industrial, apontam a relação entre o design e a sustentabilidade a partir de suas especificidades. Em linhas gerais, estas abordagens utilizam a relação entre design e sustentabilidade, tal como argumenta Manzini e

\footnotetext{
${ }^{1}$ Curau - pratos que os plantadores de cana levavam para uso no campo.

${ }^{2}$ O Complexo Industrial Portuário de Suape é considerado a locomotiva do desenvolvimento de Pernambuco e um dos principais polos de investimentos do país.

${ }^{3}$ [...] atividade criativa, que tem o objetivo de estabelecer múltiplas qualidades a objetos, processos, serviços e sistemas por todo o seu ciclo de vida. Contudo, design é o fator central da inovação humanizadora de tecnologias e um fator crucial para a troca cultural e econômica. ICSID - International Council of Societies of Industrial Design (2007) Se o design tem seu surgimento ligado à dissociação entre o projetar e o executar [tarefa delegada à indústria, que se especializou na produção repetitiva, rápida e massiva], hoje se percebe uma reaproximação do executor original: o artesão. BARROSO [2005] aponta que nos últimos anos começam a surgir intervenções cada vez mais frequentes e sistemáticas na produção artesanal, promovidas por diversos organismos da esfera pública e privada, em quase todos os países da América latina, cuja principal motivação tem sido a necessidade de integrar à vida econômica destes países uma atividade que durante muito tempo foi marginalizada e tratada apenas dentro da ótica da assistência social.
} 
Vezzoli (2005), em macro dimensões: a econômica, a produtiva, a social, a ambiental e a cultural.

No âmbito industrial, as ações do laboratório objetivam fortalecer a articulação da Universidade com o setor produtivo, visando à troca de informações entre academia e empresas, ampliando as possibilidades de atuação dos designers no Estado. Na abordagem artesanal a diretriz é firmar a atividade artesanal em Pernambuco enquanto meio de vida sustentável, através de intervenções que respeitem os valores sociais, econômicos, ambientais e culturais das comunidades produtoras de artesanato.

Inicialmente, os técnicos do Laboratório em parceria com os pesquisadores do Laboratório de Cerâmicas especiais da UFPE utilizaram o resíduo de uma fábrica de piso cerâmico como alternativa para a sustentabilidade produtiva e econômica do grupo ceramista (SILVA, 2008).

Atualmente, as pesquisas estão sendo direcionadas a utilização do resíduo da fabricação de Louças Sanitárias $\operatorname{ROCA}^{{ }^{4}}$, a fim de atender aos parâmetros de produção cerâmica para utilitários de mesa, conforme a Tabela 1. Todavia, existem alguns requisitos para a incorporação destes resíduos industriais, bem como os lodos das indústrias cerâmicas que devem ser levados em consideração, como o tratamento adequado deste resíduo, armazenamento e caracterização do mesmo. (ROCHA, et. al., 2008; MORELLI et. al., 2003; COSTA et. al., 2002)

Tabela 1 Propriedades físicas exigidas para massas de cerâmica artística, louça de mesa e louça sanitária.

\begin{tabular}{lccc}
\hline PROPRIEDADES FíSICAS & $\begin{array}{c}\text { CERÂMICA } \\
\text { ARTÍSTICA }\end{array}$ & $\begin{array}{c}\text { LOUÇA DE } \\
\text { MESA }\end{array}$ & LOUÇA SANITÁRIA \\
\hline Temperatura de Queima & 1050 0C & 1180 0C & 1250 0C \\
\hline Absorção (\%) & $15-19$ & $4-6$ & 0 \\
\hline $\begin{array}{l}\text { Módulo de Ruptura após } \\
\text { queima (Kgf/cm2) }\end{array}$ & $200-300$ & $300-500$ & Maior que 500 \\
\hline $\begin{array}{l}\text { Densidade da Barbotina } \\
\text { (g/cm3) }\end{array}$ & $1,71-1,73$ & $1,72-1,75$ & $1,77-1,80$ \\
\hline
\end{tabular}

Fonte: Adaptado de MORELLI, A.C, BALDO (2003).

Com a inserção da técnica de conformação cerâmica por colagem de barbotina, o grupo de ceramistas do Cabo está atingindo novos mercados, dentre eles, o setor gastronômico e a utilização de uma massa cerâmica adequada a tal processo é de fundamental relevância a confiabilidade do grupo no mercado.

Este artigo apresenta os primeiros resultados do Laboratório no desenvolvimento de duas massas cerâmicas adequadas à produção dos ceramistas do Cabo, a partir da inserção de percentuais do resíduo cerâmico das louças sanitárias (R2), na argila de SUAPE (S1) e matérias primas virgens para ajustes. Cumpre salientar que estudos sobre esmaltes cerâmicos, sem adição de chumbo, também veem sendo desenvolvidos em paralelo para o atender as demandas do artesanato do Cabo.

\footnotetext{
${ }^{4} \mathrm{O}$ resíduo utilizado é resultado da drenagem do processo produtivo, ou seja, água drenada do processo contendo componentes da massa: argilas, feldspatos, quartzos, entre outros elementos.
} 


\section{MATERIAIS E MÉTODOS}

\subsection{Materiais}

Foram elaboradas, inicialmente, três composições de massa, sendo uma para modelagem no torno (ET1), sinterizada à $850{ }^{\circ} \mathrm{C}$ e as demais para colagem de barbotina (EB1 e EB2), sinterizadas a $1100{ }^{\circ} \mathrm{C}$, conforme Tabela 2.

Tabela 2 - Composições das massas cerâmicas

\begin{tabular}{llll}
\hline MATÉRIAS PRIMA & ET1 & EB1 & EB2 \\
\hline Argila Cabo & $50 \%$ & $15 \%$ & $15 \%$ \\
\hline Resíduo Roca & $30 \%$ & $15 \%$ & $30 \%$ \\
\hline Feldspato & $10 \%$ & $50 \%$ & $30 \%$ \\
\hline Quartzo & $10 \%$ & $10 \%$ & $9 \%$ \\
\hline Caulim & - & $10 \%$ & $8 \%$ \\
\hline Calcita & - & - & $8 \%$ \\
\hline TOTAL & $100 \%$ & $100 \%$ & $100 \%$ \\
\hline
\end{tabular}

Fonte: Elaborado pelo autor, com base na pesquisa realizada.

\subsection{Análise química}

Esse ensaio tem como finalidade identificar as composições químicas teóricas das argilas analisadas. As amostras foram trituradas na forma de pó e uma alíquota de cada amostra foi colocada em estufa para secar a $110^{\circ} \mathrm{C}$ e então levada a uma mufla a $1000{ }^{\circ} \mathrm{C}$, por 2 horas. Para cada amostra foi feita uma pérola fundida, usando tetraborato de lítio como fundente na proporção de 1:5. As amostras foram analisadas em espectrômetro de fluorescência de raios Rigaku modelo RIX 3000, equipado com tubo de Rh, pelo método de curvas de calibração, preparadas com materiais de referência internacionais.

\subsection{Ensaios Cerâmicos}

\subsubsection{Retração Linear}

Este ensaio tem a finalidade de avaliar a redução de volume do corpo de prova após a secagem e queima além de explicar indiretamente o ensaio dimensional mencionado na NBR 15099:2004. Existem dois tipos de retração: uma que ocorre antes da queima a $110^{\circ} \mathrm{C}$ e outra que ocorre após a sinterização.

Para a realização do ensaio com a massa de barbotina, mede-se o comprimento inicial no molde (C1), em seguida, conforma-se o corpo de prova inserindo a massa na cavidade do molde. Depois do tempo adequado de fundição, ocorre o destacamento do material no molde. Na massa de torno, corta-se o tarugo compactado nas dimensões desejadas, neste estudo, $10 \mathrm{~cm}$. Os corpos de prova foram colocados na estufa para secagem na temperatura de $110^{\circ} \mathrm{C}$ durante 24 horas. 



Figura. 1 - Produção dos Corpos de prova usado nos ensaios de retração, perda ao fogo e absorção.

Fonte: Elaborado pelo autor, com base na pesquisa realizada

Após este tempo, e após resfriamento na temperatura ambiente, com o auxilio de um paquímetro, mede-se novamente os corpo-de-prova para obter o comprimento a seco (CS), Figura 1.

Em seguida, os corpos-de-prova foram levados ao forno para queima em temperatura de aproximadamente $850^{\circ} \mathrm{C}$, para a massa de torno, e a $1100{ }^{\circ} \mathrm{C}$, para a massa de colagem de barbotina, por um tempo de 8 horas, Figura 2.



Figura 2 - Sinterização e procedimentos de medição dos corpos de prova

Fonte: Elaborado pelo autor, com base na pesquisa realizada

Após a sinterização, o corpo-de-prova é medido novamente e tem-se então o comprimento queimado (CQ) do material. De posse destes valores, obtidos na experiência, podemos inserir nas equações (1), (2) e (3) para determinação da retração de secagem, de queima e total respectivamente.

Retração de secagem $(\%)=\frac{(C I-C S) \times 100}{C I}$

Retração de queima $(\%)=\frac{(C S-C Q) \times 100}{C I}$

Retração total $(\%)=\frac{(C I-C Q) \times 100}{C I}$

Onde:

$\mathrm{Cl}=$ Comprimento inicial;

$\mathrm{CS}=$ Comprimento após secagem $(110 \mathrm{oC})$;

$C Q=$ comprimento após a queima (850 e 1100 oC). 


\subsubsection{Módulo de Ruptura à Flexão}

Os moldes dos corpos de prova para ensaio de Módulo de Ruptura à Flexão foram cedidos pela fábrica de Louças Sanitárias ROCA $^{\circledR}$ e os corpos de prova para a massa de torno foram realizados numa extrusora a vácuo VERDES ${ }^{\circledR}$ modelo 057.

Todos os corpos de prova foram ensaiados numa maquina EMIC com célula de carga Trd 24 de $50 \mathrm{~N} / \mathrm{cm}^{3}$, utilizando o programa Tesc versão 3.04, conforme a norma ABNT NBR15310 - telha cerâmica, seguindo os parâmetros determinados para cada condição isto é, se o corpo de prova apresenta uma seção reta retangular ou circular, normatizado para ensaios de resistência à flexão de materiais cerâmicos avançados em temperatura ambiente Norma ASTM C1161, Figura 3.

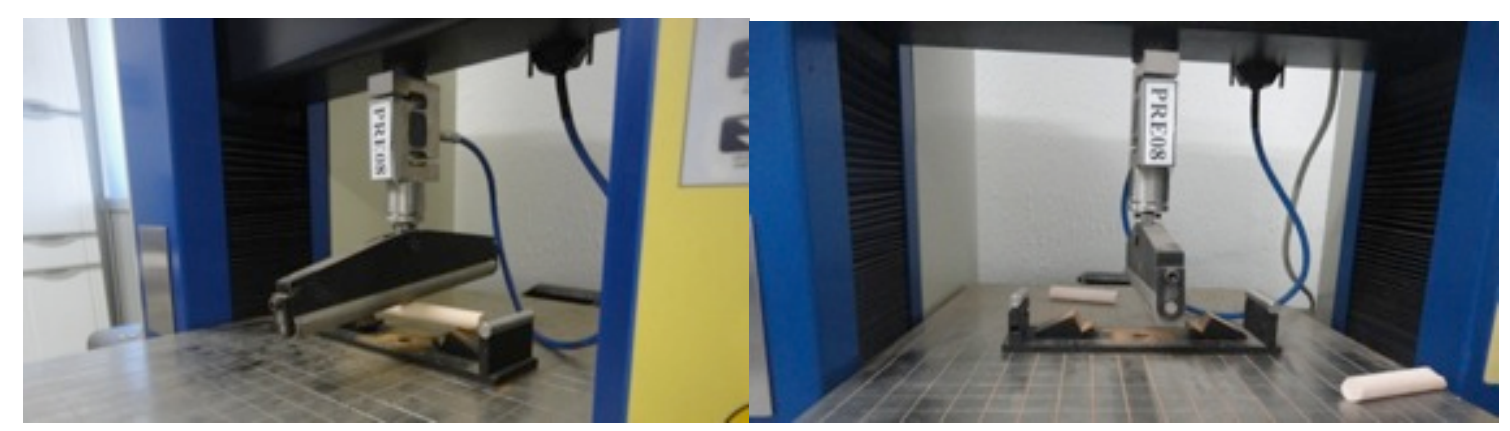

Figura 3. Ensaio de Flexão em corpo de prova de secção cilíndrica

Fonte: Elaborado pelo autor, com base na pesquisa realizada

Os valores encontrados foram lançados na equação 4 para materiais de seção retangular no caso da massa de torno e na equação 5 para as massas de barbotina cujos corpos de prova apresentavam seção reta circular e assim foram calculados os módulos de ruptura à flexão após sinterização $1100^{\circ} \mathrm{C}$.

$M R F=\frac{3 F_{F} L}{2 b d^{2}}$

Onde:

Ff: Carga necessária para ruptura em N;

L: Distância entre os pontos de suporte em cm;

b: largura do corpo de prova em $\mathrm{cm}$;

$\mathrm{d}$ : espessura do corpo de prova em $\mathrm{cm}$;

$M R F=\frac{F_{f} L}{3,1416 R^{3}}$

Onde:

Ff: Carga necessária para ruptura em N;

L: Distância entre os pontos de suporte em $\mathrm{cm}$;

$\mathrm{R}$ : raio do corpo de prova 


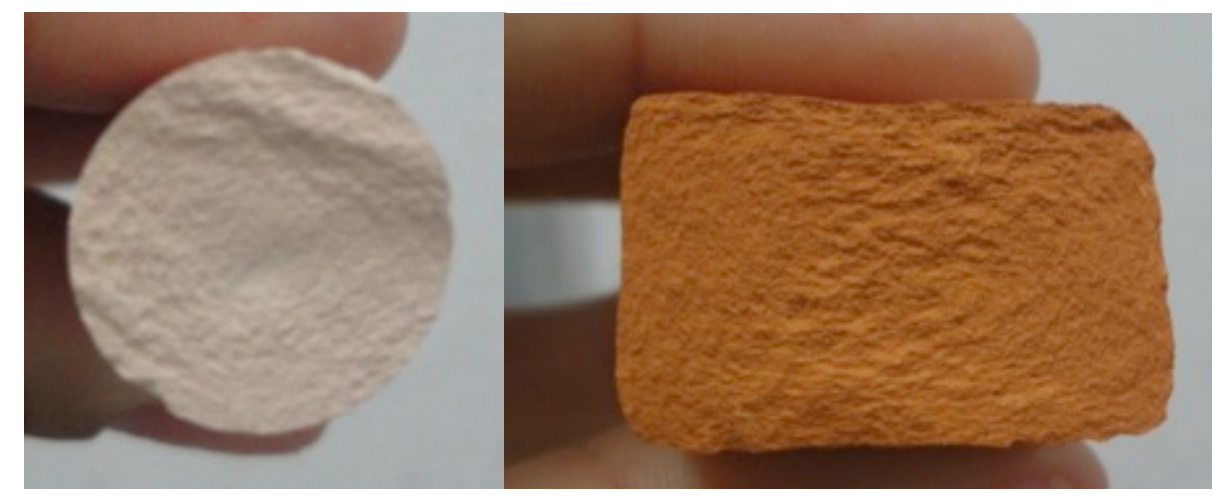

Fig. 5.

Figura 4 - Seções transversais dos corpos de prova no local da ruptura

Fonte: Elaborado pelo autor, com base na pesquisa realizada

Após a ruptura de cada corpo de prova, foram medidas as dimensões das seções transversais de cada amostra, no local da ruptura e foi observado as cargas necessárias para o rompimento, Figura 4

\subsubsection{Absorção de água (A.A.)}

Este ensaio avalia a queima da peça cerâmica, através de sua porosidade, a partir da quantidade de água absorvida pela peça cerâmica após a sinterização. 0 corpo de prova utilizado no ensaio é o mesmo usado no ensaio de retração. Este ensaio também pode ser feito com regiões distintas do produto acabado segundo ABNT NBR 15097:2004. O corpo-de-prova é pesado para determinação da massa seca (MS), logo em seguida o material é imerso em um recipiente com água, onde se eleva a temperatura da mesma até seu ponto de ebulição, permanecendo por 2 horas. Após 2 horas de fervura, deixa-se esfriar no próprio recipiente com água por 24 horas, Figura 5.

Novamente volta-se a pesar os corpos-de-prova para determinar a massa úmida (MU). De posse destes números, determinamos então o percentual de absorção, utilizando a equação (6) a seguir:

$\%$ Absorção $=\frac{(M U-M S) \times 100}{M S}$

Onde:

MS = Peso do material seco;

$\mathrm{MU}=$ Peso do material úmido 


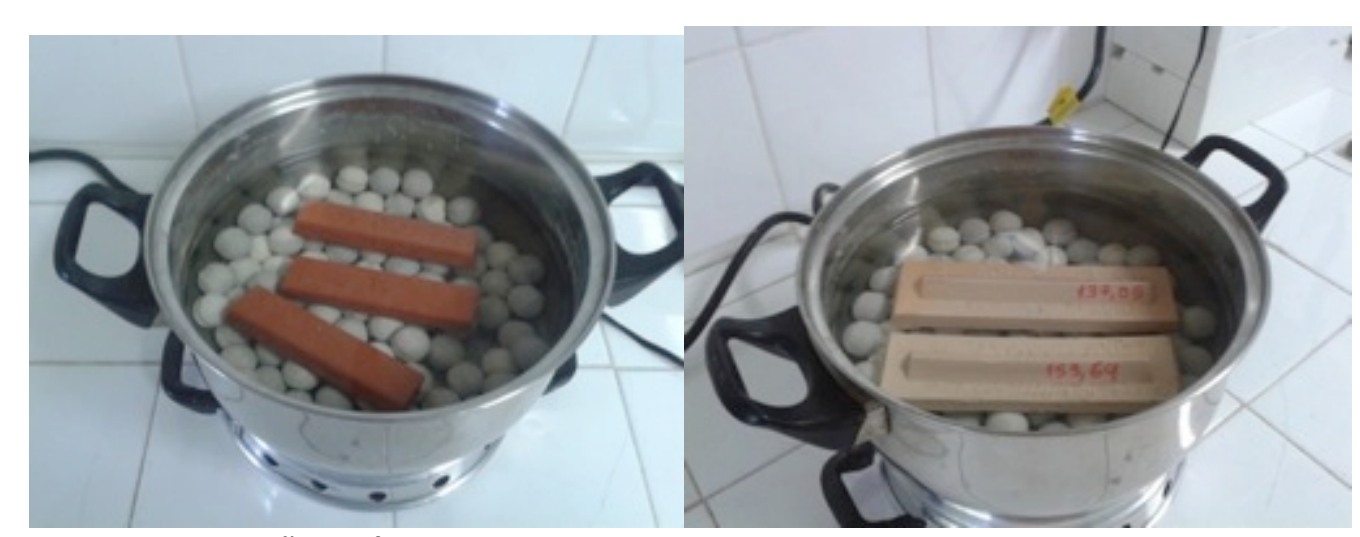

Figura 5 - Ensaio de absorção de água em ambos os corpos de prova

Fonte: Elaborado pelo autor, com base na pesquisa realizada

O valor encontrado para utensílio de mesa deve estar compreendido entre 4-6 \%. Fora desse parâmetro a peça apresentará um alto índice de porosidade e com o passar do tempo o acúmulo de umidade nos poros causará expansão por umidade, podendo haver trincas.

\subsubsection{Cor após queima}

Este ensaio consiste em avaliar a tonalidade do corpo cerâmico após a etapa de sinterização à $850{ }^{\circ} \mathrm{C}$, para massa de torno e $1100{ }^{\circ} \mathrm{C}$, para colagem por barbotina. Quando o corpo de prova é retirado da estufa, onde permaneceu por um período de 24 horas, à $110^{\circ} \mathrm{C}$, é submetidos a queima e posteriormente é avaliado com relação a cor.

\section{RESULTADOS}

\subsubsection{Análise química}

Com base na quantidade de óxidos presentes (álcalis, sílica entre outros) das amostras analisadas, Tabela 3, pode-se afirmar que tanto a argila de SUAPE quanto o resíduo industrial fornecido pela $\operatorname{ROCA}^{\circledR}$ são complementares e potencialmente capazes de servir como matéria prima para um novo composto cerâmico. Em sendo as matérias primas complementares, a inserção do R2 na massa S1 favorecerá a complementação dos álcalis $\mathrm{Na}_{2} \mathrm{O}$ e $\mathrm{K}_{2} \mathrm{O}$ responsáveis pela fusibilidade do material, entre outros óxidos, promovendo melhores propriedades tecnológicas ao produto final.

Outra consideração importante é que a argila de SUAPE apresenta um maior percentual de $\mathrm{Fe}_{2} \mathrm{O}_{3}$, que contribui para a coloração avermelhada da peça após a sinterização. Essa cor avermelhada é característica da cerâmica do Cabo e deve ser considerada na elaboração das formulações de massa. Todavia, para o processo de colagem de barbotina a cor do produto final precisa apresentar um tom mais claro, em função, da camada de esmalte cerâmico a ser aplicada. Essa condição favorece o uso de um percentual maior do R2 na formulação, tendo em vista que sua cor pós queima é acinzentada. 
Tabela 3 - Composições químicas teóricas da argila de Suape (S1) e Resíduo Roca (R2).

\begin{tabular}{ccc}
\hline DETERMINAÇÕES & \multicolumn{2}{c}{ AMOSTRAS MASSAS (\%) } \\
\cline { 2 - 3 } & $\mathrm{S} 1$ & $\mathrm{R} 2$ \\
\hline $\mathrm{SiO}_{2}$ & 56,80 & 52,65 \\
\hline $\mathrm{Al}_{2} \mathrm{O}_{3}$ & 20,31 & 21,75 \\
\hline $\mathrm{TiO}_{2}$ & 1,75 & 0,40 \\
\hline $\mathrm{Fe}_{2} \mathrm{O}_{3}$ & 7,01 & 1,92 \\
\hline $\mathrm{MgO}$ & 0,78 & 0,63 \\
\hline $\mathrm{CaO}$ & 1,18 & 3,76 \\
\hline $\mathrm{Na}_{2} \mathrm{O}$ & 0,71 \\
\hline $\mathrm{K}_{2} \mathrm{O}$ & 0,36 & 3,13 \\
\hline $\mathrm{P}_{2} \mathrm{O}_{5}$ & 2,63 & 0,30 \\
\hline $\mathrm{MnO}$ & 0,25 & Traços \\
\hline $\mathrm{ZrO}$ & 0,05 & 1,63 \\
\hline $\mathrm{BaO}$ & 0,34 & - \\
\hline $\mathrm{P} . \mathrm{F}$. & - & 11,96
\end{tabular}

Fonte: Elaborado pelo autor, com base na pesquisa realizada.

\subsubsection{Ensaios Cerâmicos}

Todos os resultados dos ensaios cerâmicos foram compilados na Tabela 4, a seguir. Todas as massas cerâmicas apresentaram densidade entre 1,65 -1,75 g/cm . Esses valores favorecem o processo de colagem de barbotina pois, diminui 0 encharcamento do molde de gesso e promove o aumento da velocidade no fluxo produção das peças. Com relação ao ensaio de retração linear, um dos dados mais importante para o processo de design, a massa de torno apresentou um maior percentual de retração na secagem $(6 \%)$ que no pós queima (2\%). No entanto, a retração total de $8 \%$ confere a para a massa de torno (ET1) um baixo percentual de retração, indicando que a adição do Quartzo e do Feldspato foi eficaz na formação de fases vítreas durante a sinterização.

Já com relação as massas para colagem de barbotina, a experiência EB1 apresentou retração total $(14,29 \%)$, considerada satisfatória. Porém, a retração no pós queima (8,5\%) foi maior que na secagem (5,71\%). A massa EB2 que contém as mesmas matérias primas da massa EB1, exceto pela adição de calcita apresentou menor variação dimensional total (6,96\%).

Quanto a resistência mecânica, a partir do ensaio de Módulo de Ruptura à Flexão, a massa ET1 apresentou melhores resultados $\left(89,24 \mathrm{Kgf} / \mathrm{cm}^{2}\right)$ quando comparado a resistência mecânica da argila de SUAPE pura $\left(24,94 \mathrm{Kgf} / \mathrm{cm}^{2}\right)$. Esse resultado comprova que a mistura um percentual de $15 \%$ do resíduo da $\operatorname{Roca}^{\circledR}$ foi satisfatória para melhoria das propriedades tecnológicas da massa, em laboratório. 
Tabela 4 - Resultados dos ensaios Cerâmicos

\begin{tabular}{lccc}
\hline TIPO DE ENSAIO & $\begin{array}{c}\text { ET1 } \\
850\left({ }^{\circ} \mathrm{C}\right)\end{array}$ & $\begin{array}{c}\text { EB1 } \\
1100\left({ }^{\circ} \mathrm{C}\right)\end{array}$ & $\begin{array}{c}\text { EB2 } \\
1100\left({ }^{\circ} \mathrm{C}\right)\end{array}$ \\
\hline $\begin{array}{l}\text { Densidade }\left(\mathrm{g} / \mathrm{cm}^{3}\right) \\
\begin{array}{l}\text { Retração secagem } \\
(\%)\end{array}\end{array}$ & 1,65 & 1,75 & 1,75 \\
\hline $\begin{array}{l}\text { Retração Queima } \\
(\%)\end{array}$ & 6 & 5,71 & 4,29 \\
\hline Retração Total (\%) & 8 & 8,50 & 2,68 \\
\hline Absorção (\%) & 19,34 & 14,29 & 6,96 \\
\hline $\begin{array}{l}\text { Módulo de ruptura } \\
\left.\text { flexão (Kgf/cm }{ }^{2}\right)\end{array}$ & 89,24 & 15,08 & 18,73 \\
\hline Cor de queima* & $\begin{array}{l}\text { Alaranjado } \\
\text { moderado }\end{array}$ & Bege & Bege \\
\hline
\end{tabular}

Fonte: Elaborado pelo autor, com base na pesquisa realizada.

(*) Cor definida por comparação com a Rock Color Chart, New York, 1984.

As massas EB1 e EB2 apresentaram valores de resistência mecânica próximos a especificação para utilitários de mesa, respectivamente 276,86 e $280,20 \mathrm{Kgf} / \mathrm{cm}^{2}$. Esses parâmetros indicam a necessidade de ajustes em alguns aspectos do processo: Inicialmente, no ajuste dos materiais fundentes para favorecer a formação das fases vítreas, ou mesmo diminuir o percentual de Calcita. Em seguida, no ajuste dos parâmetros de queima entre $1150-1180{ }^{\circ} \mathrm{C}$. Como os corpos de prova foram sinterizados a uma temperatura de $1100{ }^{\circ} \mathrm{C}$, isso também pode ter contribuído para uma resistência mecânica menor.

Com relação ao ensaio de absorção, os valores ficaram bastante próximos entre as três massas desenvolvidas: ET1(19.34 \%); EB1(15,08 \%) e EB2 (18,73 \%). Estes resultados sugerem que as massas apresentam alta porosidade necessitando de ajustes em sua composição. A calcita contida na massa EB2, embora, diminua a retração pós queima, faz com que o corpo de prova fique com uma porosidade maior.

\section{CONCLUSÕES}

A argila SUAPE é adequada para fabricação de tijolos manuais, prensados, furados, telhas e artefatos de decoração. Entretanto, em função da sua baixa resistência mecânica $\left(24,94 \mathrm{Kgf} / \mathrm{cm}^{2}\right)$ e, tendo como foco a produção de utilitários artesanais de mesa, foram necessários ajustes na composição da massa com matérias primas complementares. Para as peças de revolução confeccionadas em torno cerâmico, a adição de $15 \%$ do resíduo da fábrica de louça sanitária ROCA $^{\circledR}$ na argila de SUAPE, além de algumas matérias primas virgens para ajustes, apresentou um ganho superior a $200 \%$ na resistência mecânica do material $\left(89,24 \mathrm{Kgf} / \mathrm{cm}^{2}\right)$, melhorando também os índices de retração e de absorção de água do novo composto.

Já com relação as massas desenvolvidas para colagem de barbotina, em função dos resultados ainda não satisfatórios, EB1 (276,86 Kgf/cm² / Absorção 15,08\%) e EB2 $\left(280,20 \mathrm{Kgf} / \mathrm{cm}^{2} /\right.$ Absorção $\left.18,73 \%\right)$, a próxima etapa da pesquisa consistirá em ajustes na composição para melhorar a resistência mecânica e absorção do material. Acredita- 
se que o acréscimo de materiais fundentes como a sílica, cuja fonte principal é o quartzo pode contribuir para esse objetivo, além de aumentar a temperatura de sinterização para $1150{ }^{\circ} \mathrm{C}$.

Contudo, os artesãos do Cabo já testaram as massas ET1 e EB2, em produtos inclusive com geometria complexa, e aprovaram seu comportamento na conformação de paredes e no processo de queima. Avaliadas como satisfatórias, as massas estão sendo utilizadas na produção de utilitários de mesa, com aplicação de esmalte cerâmico e acredita-se que a adequação e a padronização dos processos de fabricação serão fundamentais para manutenção desses bons resultados.

\section{AGRADECIMENTOS}

Este trabalho é parte do projeto "Cerâmica Artesanal do Cabo de Santo Agostinho: Centro de Artesanato Arquiteto Wilson de Queiroz Campos Junior" patrocinado pelo Programa Petrobras Desenvolvimento e Cidadania.

Os autores ainda agradecem ao Laboratório Núcleo de estudos geoquímicos e o Laboratório de Frequência de Raio X ambos do Departamento de Geologia da UFPE pelas Análises Químicas. E, ao Laboratório de Caracterização de Argilas do SENAI Água Fria- Recife/PE pela produção dos corpos de prova.

\section{REFERÊNCIAS}

ANDRADE, Ana $M$; CAVALCANTI, Virginia $P$.(Coord.). Imaginário Pernambucano: design, cultura, inclusão social e desenvolvimento sustentável. Recife: Ed. Zoludesign, 2006.

BARROSO, Eduardo: 0 design como ferramenta para o incremento da joalheria brasileira. Disponível na Internet por http em http://joiabr.com.br/artigos/ebneto.html. Acesso em xx mes 2005

COSTA, M. G.; RIBEIRO, M. J.; LABRINCHA, J. A. Reutilização in situ das lamas residuais de uma indústria cerâmica, Cerâmica Industrial, Vol. 7 (5), pp. 44-50, 2002.

ICSID - International Council of Societies of Industrial Design. http://www.icsid.org/about/about/articles31.htm

MANZINI, E., VEZZOLI, C.: O desenvolvimento de produtos sustentáveis. São Paulo: Ed. Universidade de São Paulo, 2005, pp. 50 - 55

MORELLI, A.C, BALDO, J.B. Barbotinas cerâmicas contendo rejeito de vidro soda cal para maturação em baixa temperatura; Cerâmica Industrial, São Paulo, v. 8, n.3, maio/junho, 2003.

ROCHA, R.R., ZANARDO, A., MORENO, M. Estudo do comportamento reológico de barbotinas preparadas com argilas da formação Corumbataí utilizadas no polo cerâmico de Santa Gertrudes (SP). São Paulo: Cerâmica, n.54, p.332-337. 2008.

SILVA, Germannya D A et. al. Refugo industrial como insumo para a cerâmica artesanal: uma alternativa sustentável para o artesanato do Cabo de Santo Agostinho Pernambuco / Brasil. In: Congresso Internacional de Pesquisa em Design. Anais do Congresso Internacional de Pesquisa em Design. São Paulo, 2008. 